\title{
Stress Cardiomyopathy was Prone to Occur in Patients with Chronic Diseases: Maybe a Good Thing
}

Jing-Min Chong1', Hong-Jian Hou', Yan Zhang1', Xian-Cun Cao'1, Lu Fu', Yi-ting Han', Li-li Sang1', Sian E Harding², Xiu-Hua Pan' and Hong Sun ${ }^{1 *}$

${ }^{1}$ Department of Physiology, Xuzhou Medical College, China

${ }^{2}$ Faculty of Medicine, National Heart and Lung Institute, Imperial College, England

\begin{abstract}
Background : Stress Cardiomyopathy (SCM) is an increasingly reported disease as a syndrome of acute, severe, but reversible, which is commonly triggered by an acute strong physical or emotional stress. But little is known whether chronic diseases may contribute to the occurrence of SCM.

Method : The case reports about SCM from January 1998 to May 2014 were searched in the PubMed using the Medical Subject Headings: "tako-tsubo cardiomyopathy" or "stress cardiomyopathy" or "ampulla syndrome" or "apical ballooning syndrome" or "broken heart syndrome". The publications were excluded which didn't meet the inclusion criteria. SCM patients with and without chronic diseases were CD group and NCD group, respectively. The CD group was further classified into nine subgroups according to underlying chronic diseases. The circulatory diseases group which had the highest percentage in CD group was analyzed further.

Results: 1331 literatures about SCM were collected, in which 1052 documents were eligible. In these documents, 1206 patients were reported, 795 had chronic diseases, 411 had no significant past medical history. The average age in NCD group was younger than that in CD group $(57.3 \pm 0.9$ years versus $62.4 \pm 0.6$ years, $P<0.01)$. The number of SCM patients with Circulatory diseases was the most, then was Endocrine, Digestive, Respiratory, etc. The proportion of hypertension was $74.0 \%$ in circulatory diseases followed by dyslipidemia $29.3 \%$, arrhythmia $10.1 \%$, coronary artery disease $5.8 \%$, etc.
\end{abstract}

Conclusion : According to our results, the chronic diseases, especially hypertension, rose the rate of occurrence and delayed the onset age of SCM.

Keywords: Tako-tsubo cardiomyopathy; Stress cardiomyopathy; Apical ballooning syndrome; Broken heart syndrome

\section{Introduction}

Stress Cardiomyopathy (SCM), also called Tako-tsubo cardiomyopathy, broken heart syndrome or apical ballooning syndrome, is commonly triggered by an acute strong physical or emotional stress. Its most typical symptoms include acute, severe and complete heart dysfunction with reversible favourable outcomes. As we all known, the cardiovascular disease is still the leading cause of death. But the SCM has a very low death rate compared with acute coronary diseases or heart failure [1]. So, in some situations, it was considered that this reversible SCM may be a cardioprotective strategy, to avoid heart failure diseases when emergency occurs $[2,3]$.

Despite the increasing recognization of SCM, the precise pathophysiology of SCM remains unknown. High concentrations of epinephrine is thought of as the main cause of the disease [4-6], which was supported by several scholars reported that iatrogenic epinephrine could induce SCM $[7,8]$. Usually individuals with chronic diseases have higher activity of sympathetic nervous system [9-12], and the hyperactivation of sympathetic nervous system resulted in high concentrations of catecholamines [13]. So we speculated that the susceptibility to the cardiomyopathy may, in part, be related to the chronic disease.

Several studies about the relationship between SCM and other diseases have been reported. Summers MR et al. [14] reported that psychiatric illness had a high prevalence antecedes the onset of SCM. Primetshofer D et al. [15] found that SCM patients frequently suffered from neurological disease. Whether SCM is likely to prevalence in individuals with high level of catecholamines, such as chronic circulatory diseases patients, is not well understood. In this study we firstly assessed the relationship between chronic diseases and SCM systematically by documenting a large number of SCM cases that have been reported in the literatures.

\section{Method}

Case reports about SCM from January 1998 to May 2014 were searched in Pubmed by using the Medical Subject Headings with no language restrictions: "Tako-tsubo cardiomyopathy" or "stress cardiomyopathy" or "ampulla syndrome" or "apical ballooning syndrome" or "broken heart syndrome". All the files searched were manually reviewed by five investigators. The publications were excluded from the study if: (1) it was not written in English or Chinese; (2) it was not case report of SCM; (3) the age and sex of a patient were not clearly described; (4) case reports were repeated in different articles. The age, sex, chronic diseases of every SCM patient were collected using the Office Excel Software. The SCM patients were

*Corresponding authors: Hong Sun, Department of Physiology, Xuzhou Medica College, 209 Tongshan Rd, Xuzhou, 221004, China, Tel: +86-516-83262618; Fax: +86-516-83262858; E-mail: sunh@xzmc.edu.cn

Received December 19, 2015; Accepted February 17, 2016; Published February 24, 2016

Citation: Chong JM, Hou HJ, Zhang Y, Cao XC, Fu L, et al. (2016) Stress Cardiomyopathy was Prone to Occur in Patients with Chronic Diseases: Maybe a Good Thing. Cardiovasc Pharm Open Access 5: 174. doi:10.4172/23296607.1000174

Copyright: ( 2016 Chong JM, et al. This is an open-access article distributed under the terms of the Creative Commons Attribution License, which permits unrestricted use, distribution, and reproduction in any medium, provided the original author and source are credited. 
divided into two groups: Chronic Diseases group (CD) and Non Chronic Diseases group (NCD). The criteria of chronic diseases should contain at least one of the following items: (1) chronic illnesses were diagnosed; (2) the patients were taking some chronic diseases drugs; (3) some chronic diseases just such as cholecystolithiasis was found during hospitalization for SCM; (4) the patients underwent an operation within two months; (5) the patients were on continuous treatment of radiotherapy or chemotherapy after surgery for cancer; (6) the patients had cardiac surgery and cardiac interventional therapy like pacemaker implantation or radiofrequency ablation.

CD group was further classified into nine subgroups as follows: Circulatory, Endocrine, Digestive, Respiratory, Psychological, Nervous, Locomotor, Urinary and other group. The 'other group' contained reproductive diseases, hematological diseases, systemic diseases, skin diseases, etc.

\section{Statistical analysis}

Data was collected by Office Excel Software and statistical analysis was carried out by Graphpad prism 5.0. Results were presented as mean \pm SEM or number of patients (\%) and their corresponding $95 \%$ confidence intervals $(95 \% \mathrm{CI})$. The continuous variables with normal distributions were analyzed by using independent T-test and the categorical data was analyzed by using Chi-square test, then partition of chi-square was conducted to multiple comparisons of rates. Statistical significance was set at $P<0.05$, except when partition of chi-square was used for multiple comparisons among groups, in which case, statistical significance was set at $P<0.05 / \mathcal{C}_{1}^{2}=0.0011, P<0.05 / \mathcal{C}_{8}^{2}=0.0018$ and $P<0.05 / \mathcal{C}_{7}^{2}=0.0024$.

\section{Results and Discussions}

\section{Gender and age discrepancy in SCM}

In this study, out of 1331 documents (71 written in Chinese and 1260 written in English) about SCM reported from January 1998 to May 2014, 1206 SCM patients were found. And in these patients, most of them were over 50 years old $(77.7 \%)$, in which female were 834 (69.2\%) (Figure 1A). The average age of female was higher than that of male $(61.9 \pm 0.5$ years versus $53.0 \pm 1.5$ years, $P<0.01)$, and female were more in each corresponding age interval over 20 years old. We also found, in female, the numbers of SCM patients were quite different among age groups, being highest in group $60 \sim 69$ and $70 \sim 79$. The variance of patients' number among age groups in male didn't show much difference as in female (Figure 1B). These results demonstrated that most SCM patients were aged female.

The marked gender discrepancy was also observed by other investigators $[16,17]$. The pathophysiological mechanism of SCM was still not clear, but it is thought to be related to sympathetic nervous system and excessive catecholamines, mainly epinephrine [4-8,18]. Epinephrine has a higher affinity for the $\beta_{2}$ ARs [2], which distribute in the myocardium, and the number of this receptors progressively increases from the base to the apex of heart. $\beta_{2} \mathrm{AR}$ through Gi signaling pathway exert negative inotropic effects, leading to myocardial contraction inhibition [2], which was more obvious on the apex of heart. When met with stress, the excessive inhibition effect on the heart will contribute to the occurrence of SCM [19]. In addition, in female, estrogen increases the ratio of $\beta_{2} A R$ in $\beta A R$ [20], which enhances the $\beta_{2}$ AR-Gi signaling pathway. This might account for the higher vulnerability to SCM in females.

Studies have shown that catecholamine-responsiveness in the elderly especially post menopause women had an age-associated decrease, while the dissociative catecholamines in the circulation which play the main roles increased with advancing age. On the other hand, as estrogen declines with the age, its inhibition effect on the sympathetic system decreases [21,22], which lead to higher concentration of catecholamines in the circulative system. The increase of dissociative catecholamines may be the reason why post menopause women were more susceptible to SCM than pre-menopause women. It was reported [23] that women under stress were more resistant to cardiac toxicity caused by catecholamine. When meet massive release of catecholamine, they only undergo reversible SCM. Thus, SCM maybe a good thing, comparing with heart failure that is more likely to happen directly in men.

As we have stated above, in female, the numbers of SCM patients were highest in group $60 \sim 69$ and $70 \sim 79$, while the number of SCM patients decreased after age 79 .
A

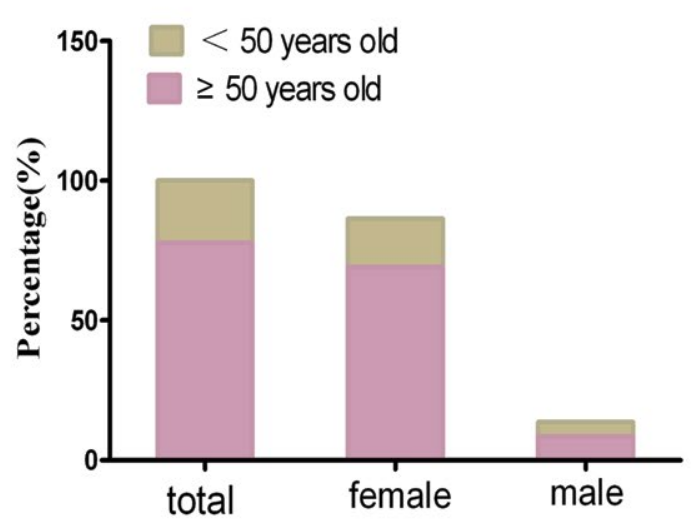

B

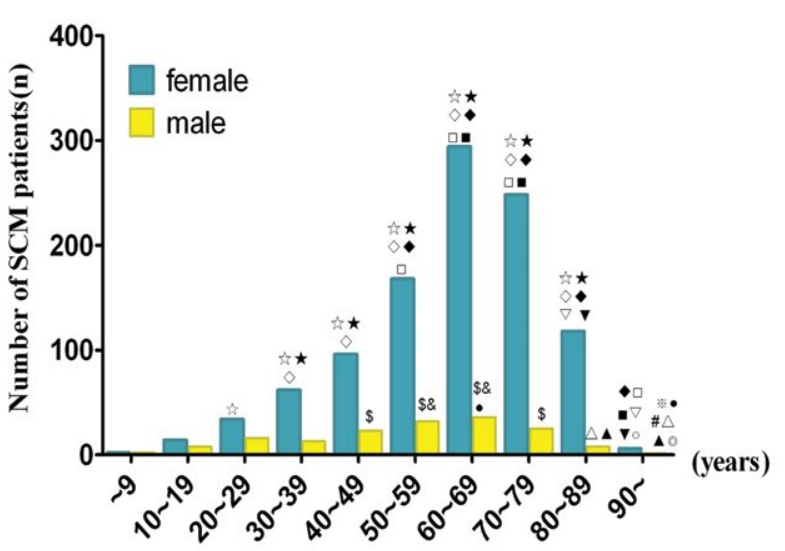

Figure 1: A The percentage of SCM patients over and under 50 years old in total, female and male. Each value represented the percentage of SCM patients ; $\mathbf{B}$. The age distribution of SCM in male and female. Each value represented the number of SCM patients. In females, $P<0.05 / C_{11}^{2}=0.0011 ;{ }^{\star} P<0.0011$ versus $\sim 9 ;{ }^{\star} P<0.0011$ versus $10 \sim 19 ; \diamond P<0.0011$ versus $20 \sim 29 ; \bullet P<0.0011$ versus $30 \sim 39 ; \square P<0.0011$ versus $40 \sim 49 ; \cdot P<0.0011$ versus $50 \sim 59 ; \nabla P<0.0011$ versus $60 \sim 69 ; \nabla P<0.0011$ versus 70 79; ${ }^{\circ} P<0.0011$ versus $80 \sim 89$; In males, $P<0.05 / c_{11}=0.0011 ;{ } P<0.0011$ versus $\sim 9 ; \& P<0.0011$ versus $10 \sim 19 ; * P<0.0011$ versus $20 \sim 29 ; \cdot P<0.0011$ versus $30 \sim 39 ; \# P<0.0011$ versus $40 \sim 49 ; \triangle P<0.0011$ versus $50 \sim 59 ; \triangle P<0.0011$ versus $60 \sim 69 ; \odot P<0.0011$ versus $70 \sim 79$. 
World Health Organization (WHO) reported that the number of aged people (> 60 years old) was 605 million in 2000 [24]. While the people over 80 years old were only 98.75 million in the same year [24]. Therefore, we speculated that the reason of the number of SCM patients after age 79 declined was that the population of aged people (> 80 years old) decreased.

\section{SCM profile in patients with chronic diseases}

Based on our data, $65.9 \%$ SCM patients had chronic diseases (795 patients, $\mathrm{CI}=64.5 \%-67.3 \%$ ), which is nearly twice more than those without chronic diseases $(34.1 \%, 411$ patients, CI $=32.7 \%-35.5 \%)$ (Figure 2A). It was reported that the rate of chronic diseases was 19.99\% in 2008 in China [25]. And it was 49.8\% in US [26] in 2012. Thus, the chronic diseases were higher in the SCM population. Maybe the chronic diseases boost the occurrence of SCM.

It has been known that the activity of sympathetic nervous system increased in some chronic diseases (such as, hypertension [9], heart failure [10], chronic kidney disease [11], COPD [12]). The hyperactivation of sympathetic nervous system resulted in high concentrations of catecholamines in circulation [13]. High level of catecholamines triggered a switch of $\beta_{2} \mathrm{AR}$ coupling from $\mathrm{Gs}$ to $\mathrm{Gi}$ signaling pathway in SCM [2]. The $\beta_{2} \mathrm{AR}-\mathrm{Gs}$ pathway could activate cAMP to enhance cardial contractility, and the $\beta_{2}$ AR-Gi signaling pathway exerts negative inotropic effect via PI3K [27,28]. The balance of Gs and Gi proteins signaling pathway plays a key role in keeping cardiomyocytes contracting regularly. The expression of $\mathrm{Gi}$ would increase if $\beta A R$ is stimulated persistently by catecholamines [29], high level of circulating catecholamines further trigger more activation of $\beta_{2}$ AR-Gi signaling pathway leading to SCM [2]. $\beta_{2} \mathrm{AR}-$ Gi signaling pathway inhibits the myocardial contraction and reduce oxygen consumption and antiapoptotic effect which was considered as a protective mechanism $[2,3,27,28]$. These may be vital to resist the effects of excessive catecholamines in sudden stress attack, leading to occurrence of transient heart dysfunction in the people with chronic diseases rather than fatal acute heart failure.

Chronic diseases may lead to $\beta A R$ insensitivity [13]. Long-term $\beta A R$ insensitivity in turn increased the release of sympathetic nervous system. This may delayed the onset age of SCM patients with chronic diseases. So, the average age of SCM patients in NCD group was lower than that in $\mathrm{CD}$ group $(57.3 \pm 0.9$ years versus $62.4 \pm 0.6$ years, $P<$ 0.01) (Figure 2B)).

We further divided CD group (795 patients) into nine subgroups as Circulatory, Endocrine, Digestive, Respiratory, etc. We found the number of SCM patients was the highest in Circulatory group (497 patients, $62.5 \%$, CI $=60.8 \%-4.2 \%$ ), followed by Endocrine group (179 patients, $22.5 \%$, CI $=21.0 \%-24.0 \%$ ), Digestive (114 patients, $14.3 \%$, $\mathrm{CI}=3.1 \%-15.6 \%)$, Respiratory (102 patients, $12.8 \%, \mathrm{CI}=11.6 \%$ $14.0 \%$ ), Psychological ( 89 patients, $11.2 \%, \mathrm{CI}=10.1 \%-12.3 \%$ ), Nervous (87 patients, $10.9 \%, \mathrm{CI}=9.8 \%-12.1 \%$ ), Locomotor (50 patients, $6.3 \%$, $\mathrm{CI}=5.4 \%-7.2 \%)$, Urinary ( 42 patients, $5.3 \%, \mathrm{CI}=4.5 \%-6.1 \%)$ and Other group ( 89 patients, $11.2 \%, \mathrm{CI}=10.1 \%-12.3 \%$ ) (Figure 3 ). The proportions in Digestive, Respiratory, Psychological, Nervous groups had no significant difference. But they were all higher compared with Locomotor and Urinary group. There was no difference between the Locomotor and Urinary group.

Studies have shown that SCM was associated with chronic psychological or neurological diseases [14,15]. Our results implied that the influence of the chronic circulatory diseases on SCM may be underestimated. Summers et al. reported that majority of SCM patients suffered at least two cardiovascular risk factors, including hypertension, hyperlipidemia, diabetes mellitus, history of smoking, or a family history of cardiovascular disease [14]. This indicated that long-term burden of cardiovascular diseases may exert important influence on SCM. Studies have proved that chronic circulatory diseases sustained activation of sympathetic nervous system, therefore reducing its excitability [30]. This change may result in a slow response to external stimulation. Thus, the heart appears to have a sub-optimal response, hence a transient and reversible dysfunction.

\section{Prevalence of hypertension in SCM patients}

We further evaluated the proportion of different chronic circulatory diseases in SCM patients. Hypertension had the highest 74.0\% (368 patients, $\mathrm{CI}=72.1 \%-76.0 \%)$, followed by dyslipidemia $29.3 \%(146$ patients, $\mathrm{CI}=27.3 \%-31.5 \%$ ), arrhythmia $10.1 \%$ (50 patients, $\mathrm{CI}=8.7 \%$ $11.5 \%$ ), coronary artery disease $5.8 \%$ (29 patients, $\mathrm{CI}=4.8 \%-6.9 \%)$, thrombus $4.2 \%$ ( 21 patients, $\mathrm{CI}=3.3 \%-5.1 \%$ ), valvular disease $2.8 \%$ (14 patients, $\mathrm{CI}=2.1 \%-3.6 \%)$, peripheral vascular disease $2.6 \%(13$ patients, CI $=1.9 \%-3.3 \%$ ) (Figure 4 ). Meanwhile, they accounted for $30.5 \%$ (hypertension), $12.1 \%$ (dyslipidemia), $4.1 \%$ (arrhythmia), $2.4 \%$ (coronary artery disease), 1.7\% (thrombus), 1.2\% (valvular disease), $1.1 \%$ (peripheral vascular disease) in total SCM patients, respectively. Kurisu $S$ et al. reported that hypertension account for 35.3\% (36/102) in SCM patients, similar to our results [17].

Our result have shown that the SCM was easier to occur in the post menopause women and in the hypertension patients. Studies reported that the decline of $\beta \mathrm{AR}$ sensitivity in cardiac muscle was associated with aging $[31,32]$, which lead to the $\beta A R$-mediated decline in vasoreactivity [33]. The age-related decrease of $\beta A R$ vasoreactivity
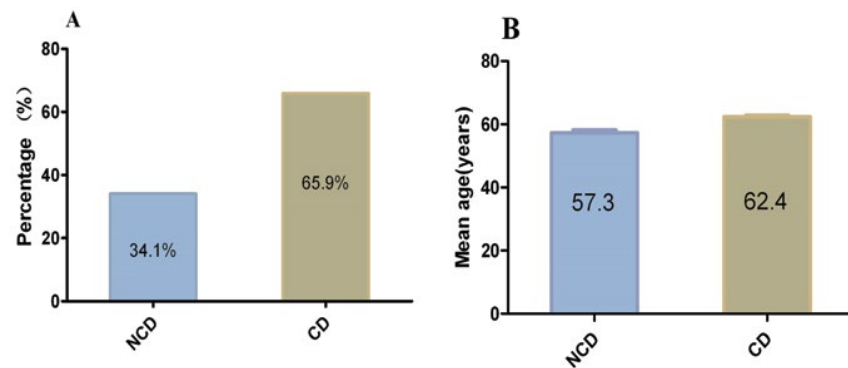

Figure 2: A. The percentage of SCM patients with or without chronic diseases. B. The mean age of SCM patients with or without chronic diseases. CD, SCM patients with chronic diseases; NCD, SCM patients without chronic diseases.

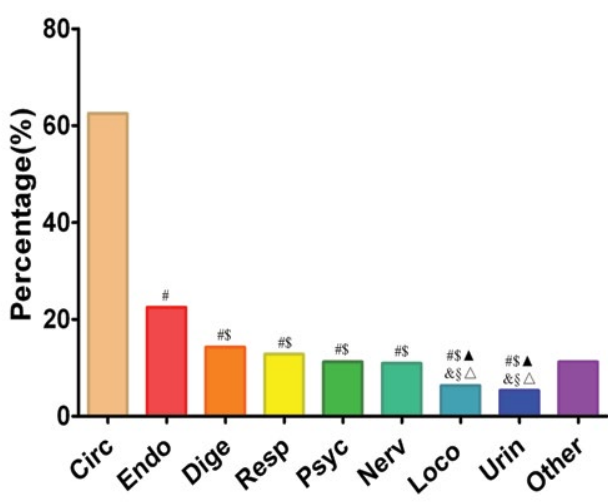

Figure 3: The percentage of different chronic diseases in SCM patients. Each value represents the percentage of SCM patients. $P<0.05 / c_{8}^{2}=0.0018$. ${ }^{\sharp} P<0.0018$ versus Circ, ${ }^{\$} P<0.0018$ versus Endo, ${ }^{\wedge} P<0.0018$ versus 


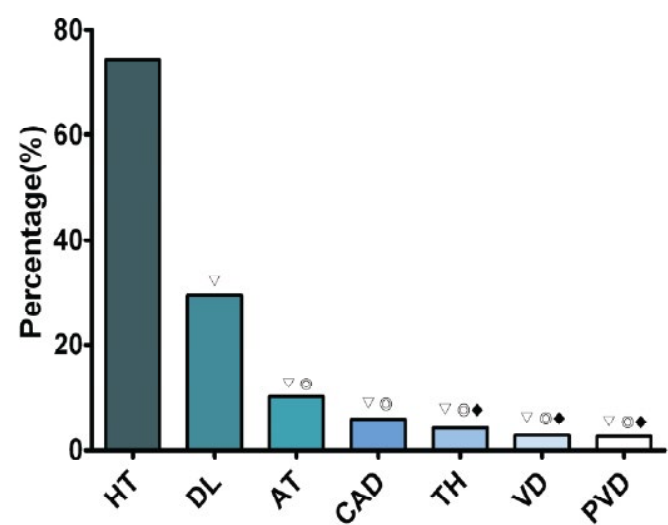

Figure 4: The percentage of different chronic circulatory diseases in SCM patients. Each value represents the percentage of SCM patients. $P<0.05 / c_{7}=0.0024$ $\nabla P<0.0024$ versus $\mathrm{HT}$; $\odot P<0.0024$ versus $\mathrm{DL}$; $\bullet P<0.0024$ versus AT; HT, Hypertension; DL, Dyslipidemia; AT, Arrhythmia; CAD, Coronary Artery Disease; TH, Thrombus; VD, Valvular Disease; PVD, Peripheral Vascular Disease.

is a common factor underlying hypertension $[34,35]$. The reason may be associated with one of the G protein coupled receptor kinase GRK2. The GRK2 was abundantly expressed in the heart and in the vessels [36,37]. It was reported that the expression level of GRK2 enhanced in hypertensive patients [35], and the increased level of GRK2 appear to participate in the desensitization of $\beta \mathrm{AR}$ and the reduction of $\beta \mathrm{AR}$ mediated physiological responses [38,39]. Additionally, GRK2 also could phosphorylate $\beta_{2}$ AR leading the receptor to Gi-biased signaling pathway [40]. The lower $\beta_{2} A R$ reactivity to the high concertration of catecholamines as a result of the decreased of $\beta_{2} \mathrm{AR}$ process, together with the increased of $\mathrm{Gi}$ signaling pathway may explain why the hypertensive individuals were were more easier to occur SCM when met with stress.

Sympathetic nervous system activation participates in initiating and sustaining the blood pressure elevation [9]. At the same time, the decreased number and function of $\beta_{1} A R$, relatively increased the activity of $\beta_{2} \mathrm{AR}$ in the heart [41] in the hypertensive individuals. This results were supported by Witte et al. [42] who found that the total density of $\beta A R$ in the membrane of cardiomyocytes declined significantly, due to the decline of the density of $\beta_{1} \mathrm{AR}$ in spontaneous hypertension. Therefore, when met with stress, instantaneous emergence of a large number of catecholamines activate more $\beta_{2} \mathrm{AR}$ in hypertensive patients. This may partly explain why hypertension, alone or in association with other chronic diseases was the most common circulatory chronic disease in SCM patients.

\section{Conclusion}

In this study, we found that strong short-term emotional or physical stress triggered SCM was prone to occur in patients with chronic diseases, especially hypertension. We postulated that sustaining high concentration of catecholamines desensitized $\beta$-adreonoceptors of heart or changed their expression, which reduced the response to stress induced higher catecholamines. Therefore, when met with stress, these individuals easily happened reversible heart failure--SCM, instead of fatal heart diseases. This maybe a good thing.

\section{Funding}

This research received grant from the National Natural Science Foundation of China (No. 81370329); UK-China Stem Cell Partnership Initiative (No.81461138036); Graduate student innovation project in Jiangsu province
(CXZZ13_0982); A project funded by the Priority Academic Program Development of Jiangsu Higher Education Institutions (PAPD).

\section{Acknowledgement}

The author would like to thank Medical Statistics analysis Center of Xuzhou Medical College for giving a contribution to the data analysis.

\section{References}

1. Gianni M, Dentali F, Grandi AM, Sumner G, Hiralal R, et al. (2006) Apical ballooning syndrome or takotsubo cardiomyopathy: a systematic review. Eur Heart J 27: 1523-1529.

2. Lyon AR, Rees PS, Prasad S, Poole-Wilson PA, Harding SE (2008) Stress (Takotsubo) cardiomyopathy - a novel pathophysiological hypothesis to explain catecholamineinduced acute myocardial stunning. Nat Clin Pract Cardiovasc Med 5: 22-29.

3. Nef HM, Möllmann H, Troidl C, Kostin S, Voss S, et al. (2009) Abnormalities in intracellular $\mathrm{Ca}^{2+}$ regulation contribute to the pathomechanism of Tako-Tsubo cardiomyopathy. Eur Heart J 30: 2155-2164.

4. Sharkey SW, McAllister N, Dassenko D, Lin D, Han K, et al. (2015) Evidence That High Catecholamine Levels Produced by Pheochromocytoma May be Responsible for Tako-Tsubo Cardiomyopathy. Am J Cardiol 115: 1615-1618.

5. Prasad A, Lerman A, Rihal CS (2008) Apical ballooning syndrome (Tako-Tsubo or stress cardiomyopathy): a mimic of acute myocardial infarction. Am Heart $\mathrm{J}$ 155: 408-417.

6. Wittstein IS, Thiemann DR, Lima JA, Baughman KL, Schulman SP, et al. (2005) Neurohumoral features of myocardial stunning due to sudden emotional stress. N Engl J Med 352: 539-548.

7. Abraham J, Mudd JO, Kapur NK, Klein K, Champion HC, et al. (2009) Stress cardiomyopathy after intravenous administration of catecholamines and betareceptor agonists. J Am Coll Cardiol 53: 1320-1325.

8. Litvinov IV, Kotowycz MA, Wassmann S (2009) latrogenic epinephrine-induced reverse Takotsubo cardiomyopathy: direct evidence supporting the role of catecholamines in the pathophysiology of the "broken heart syndrome". Clin Res Cardiol 98:457-462.

9. Esler M (2000) The sympathetic system and hypertension. Am J Hypertens 13: $99 \mathrm{~S}-105 \mathrm{~S}$

10. Florea VG, Cohn JN (2014) The autonomic nervous system and heart failure. Circ Res 114: 1815-1826.

11. De Beus E, de Jager R, Joles JA, Grassi G, Blankestijn PJ (2014) Sympathetic activation secondary to chronic kidney disease: therapeutic target for renal denervation? J Hypertens 32: 1751-1761.

12. Andreas S, Haarmann H, Klarner S, Hasenfuss G, Raupach T (2014) Increased sympathetic nerve activity in COPD is associated with morbidity and mortality. Lung 192: 235-241.

13. Baker AJ (2014) Adrenergic signaling in heart failure: a balance of toxic and protective effects. Pflugers Arch 466: 1139-1150.

14. Summers MR, Lennon RJ, Prasad A (2010) Pre-morbid psychiatric and cardiovascular diseases in apical ballooning syndrome (tako-tsubo/stress-induced cardiomyopathy): potential pre-disposing factors? J Am Coll Cardiol 55:700-701.

15. Primetshofer D, Agladze R, Kratzer H, Reisinger J, Siostrzonek P (2010) TakoTsubo syndrome: an important differential diagnosis in patients with acute chest pain. Wien Klin Wochenschr 122: 37-44

16. Kurisu S, Kihara Y (2012) Tako-tsubo cardiomyopathy: clinical presentation and underlying mechanism. J Cardiol 60: 429-437.

17. Kurisu S, Inoue I, Kawagoe T, Ishihara M, Shimatani Y, et al. (2010) Presentation of Tako-tsubo cardiomyopathy in men and women. Clin Cardiol 33: 42-45.

18. Nef HM, Möllmann H, Akashi YJ, Hamm CW (2010) Mechanisms of stress (Takotsubo) cardiomyopathy. Nat Rev Cardiol 7: 187-193.

19. Paur H, Wright PT, Sikkel MB, Tranter MH, Mansfield C, et al. (2012) High levels of circulating epinephrine trigger apical cardiodepression in a $\beta 2$-adrenergic receptor/Gi-dependent manner: a new model of Takotsubo cardiomyopathy. Circulation 126: 697-706.

20. Nguyen SB, Cevik C, Otahbachi M, Kumar A, Jenkins LA, et al. (2009) Do comorbid psychiatric disorders contribute to the pathogenesis of tako-tsubo syndrome? A review of pathogenesis. Congest Heart Fail 15: 31-34. 
Citation: Chong JM, Hou HJ, Zhang Y, Cao XC, Fu L, et al. (2016) Stress Cardiomyopathy was Prone to Occur in Patients with Chronic Diseases: Maybe a Good Thing. Cardiovasc Pharm Open Access 5: 174. doi:10.4172/2329-6607.1000174

21. He XR, Wang W, Crofton JT, Share L (1998) Effects of 17beta-estradiol on sympathetic activity and pressor response to phenylephrine in ovariectomized rats. Am J Physiol 275: R1202-1208.

22. Santulli G, laccarino G (2013) Pinpointing beta adrenergic receptor in ageing pathophysiology: victim or executioner? Evidence from crime scenes. Immun Ageing 10: 10.

23. Stöllberger C, Finsterer J (2011) Why does takotsubo ("broken heart syndrome") affect more females than males? Int J Cardiol 147: 175-176.

24. www.who.int/ageing/about/facts/en/

25. www.moh.gov.cn/mohbgt/s3582/200902/39201.shtm

26. Ward BW, Schiller JS, Goodman RA (2014) Multiple chronic conditions among US adults: a 2012 update. Prev Chronic Dis 11: E62.

27. Raake PW, Vinge LE, Gao E, Boucher M, Rengo G, et al. (2008) G proteincoupled receptor kinase 2 ablation in cardiac myocytes before or after myocardial infarction prevents heart failure. Circ Res 103: 413-422.

28. Woo AY, Xiao RP (2012) B-Adrenergic receptor subtype signaling in heart: from bench to bedside. Acta Pharmacol Sin 33: 335-341.

29. Wang XX, Feng YB (2001) [Recent advances in cardiac beta 2-adrenergic receptor]. Sheng Li Ke Xue Jin Zhan 32: 262-264.

30. Parati G, Esler M (2012) The human sympathetic nervous system: its relevance in hypertension and heart failure. Eur Heart J 33: 1058-1066.

31. Xiao RP, Lakatta EG (1992) Deterioration of beta-adrenergic modulation of cardiovascular function with aging. Ann N Y Acad Sci 673: 293-310.

32. Santulli G, laccarino G (2013) Pinpointing beta adrenergic receptor in ageing pathophysiology: victim or executioner? Evidence from crime scenes. Immun Ageing 10: 10 .

33. Burger D, Kwart DG, Montezano AC, Read NC, Kennedy CR, et al.( 2012) Microparticles induce cell cycle arrest through redox-sensitive processes in endothelial cell: implications in vascular senescence. J Am Heart Assoc 1:e001842.
34. Santulli G, Cipolletta E, Sorriento D, Del Giudice C, Anastasio A, et al. (2012) CaMK4 Gene Deletion Induces Hypertension. J Am Heart Assoc 1: e001081.

35. Izzo R, Cipolletta E, Ciccarelli M, Campanile A, Santulli G, et al. (2008) Enhanced GRK2 expression and desensitization of betaAR vasodilatation in hypertensive patients. Clin Transl Sci 1: 215-220.

36. laccarino G, Campanile A, Stantulli G, Zuppieri F, Koch W (2006) G proteincoupled receptor kinases and hypertension: a review of disease mechanisms. High Blood Press Cardiovasc Prev 13: 151-158.

37. Penela P, Ribas C, Mayor F Jr (2003) Mechanisms of regulation of the expression and function of G protein-coupled receptor kinases. Cell Signal 15: 973-981.

38. Eckhart AD, Ozaki T, Tevaearai H, Rockman HA, Koch WJ (2002) Vasculartargeted overexpression of $\mathrm{G}$ protein-coupled receptor kinase-1 in transgensic mice attenuates beta-adrenergic receptor signaling and increases resting blood pressure. Mol Pharmacol 61:749-758.

39. Koch WJ, Rockman HA, Samama P, Hamilton RA, Bond RA, et al. (1995) Cardiac function in mice overexpressing the beta-adrenergic receptor kinase or a beta ARK inhibitor. Science 268: 1350-1353.

40. Zhu W, Petrashevskaya N, Ren S, Zhao A, Chakir K, et al. (2012) Gi-biased $\beta 2 A R$ signaling links GRK2 upregulation to heart failure. Circ Res 110: 265-274

41. Bristow M, Ginsburg R, Umans V, Fowler M, Minobe W, et al. (1986) $\beta 1$ - and $\beta 2$ adrenergic-receptor subpopulations in nonfailing and failing human ventricular myocardium:coupling of both receptor subtypes to muscle contraction and selective down-regulation in heartfailure. Circ Res 59:297-309.

42. Witte K, Parsa-Parsi R, Vobig M, Lemmer B (1995) Mechanisms of the circadian regulation of beta-adrenoceptor density and adenylyl cyclase activity in cardiac tissue from normotensive and spontaneously hypertensive rats. J Mol Cell Cardiol 27:1195-202. 